\title{
Determinants of airway responsiveness to histamine in children
}

\author{
S.W. Turner*, L.J. Palmer\#, P.J. Rye*, N.A. Gibson*, S. Young*, J. Goldblatt*, \\ L.I. Landau* and P.N. Le Souëf*
}

ABSTRACT: Increased airway responsiveness (AR) is associated with asthma, but not all individuals with increased AR have asthma. The aim of this study was to identify factors, other than physician-diagnosed asthma (PDA), which are associated with increased AR.

In a longitudinal study, data were collected on atopy and lower respiratory tract illness (LRTI) in infancy, and AR (expressed as dose-response slope (DRS)), atopy, tobacco-smoke exposure and PDA in childhood.

At age 6 yrs, DRS was assessed in 102 children, of whom 22 (22\%) had PDA; the corresponding figures at 11 yrs of age were 176 and $29(15 \%)$. At age 6 yrs, DRS was significantly associated with PDA, current atopy and parental smoking $(n=83)$. At age $11 \mathrm{yrs}$, DRS was significantly associated with PDA, current atopy and LRTI in the first six months $(n=75)$. There was a significant positive interaction between atopy at age 12 months and PDA age 11 yrs.

In conclusion, these data suggest that factors other than asthma or atopy may determine the level of airway responsiveness in children. In children with asthma, airway responsiveness may be influenced by the early onset of atopy. The current findings may explain the inconsistent relationship between airway responsiveness and asthma.

KEYWORDS: Asthma, atopy, bronchial hyperreactivity, child, respiratory infection, tobacco smoke

$\mathbf{T}$ here is a strong positive relationship between airway responsiveness (AR) and childhood asthma, but not all children with increased AR have asthma [1, 2], indicating the presence of mechanisms for AR that are independent of asthma. In children, AR has been positively associated with many factors other than asthma, including atopy in infancy [3] and childhood [4], the male sex in young children [5, 6], and the female sex in teenagers [7]. A parental history of asthma has also been positively associated with AR in children [8], suggesting that genetic or environmental factors within the family influence AR. A small number of genetic polymorphisms have been associated with altered AR in children [9, 10], and environmental factors positively associated with AR include low dietary fish consumption [8], exposure to tobacco smoke [11, 12] and lower respiratory tract infections before 2 yrs of age [8]. It is unclear which factors associated with AR act independently of asthma, and understanding of this issue may explain the inconsistent relationship between asthma and increased AR.

A birth cohort that initially numbered 253 individuals has undergone longitudinal assessments of many factors associated with childhood AR [13]. The presence of physician-diagnosed asthma (PDA) and AR (as evidenced by dose-response slope (DRS) to histamine) has also been determined in cohort members aged 6 and 11 yrs. In this study, the hypothesis that factors could be identified which influence childhood DRS independently of asthma was tested.

\section{METHODS \\ Subjects}

Individuals were recruited from among expectant parents attending an antenatal clinic at a local metropolitan clinic (Osborne Park Hospital, Perth, Australia) [13]. There was no selection for parental asthma. Exclusion criteria included infants born prematurely (i.e. before 36 weeks gestation) or those who developed respiratory symptoms in the first month of life. Informed consent was obtained from parents. The study was approved by the Medical Ethics Committee of Princess Margaret Hospital for Children, Perth, Australia.

\section{Protocol}

At enrolment, a history of PDA in either parent was noted. At the ages of 1, 6 and 12 months,
AFFILIATIONS

${ }^{*}$ School of Paediatrics and Child Health, and

\#West Australia Institute for Medical Research, University of Western Australia, Perth, Australia.

CORRESPONDENCE

S.W. Turner

School of Medicine Dept of Child Health Royal Aberdeen Children's Hospital Foresterhill

Aberdeen AB25 2ZG

UK

Fax: 441224551919

E-mail: s.w.turner@abdn.ac.uk

Received:

April 212004

Accepted after revision:

November 102004

SUPPORT STATEMENT

S.W. Turner was supported by the

National Health and Medical

Research Council of Australia,

Canberra, Australia. 
infants underwent an assessment that included skin-prick reactivity. A history of lower respiratory tract illness (LRTI) during infancy was determined from monthly questionnaires prospectively completed by parents. At age 6 and 11 yrs, individuals underwent an assessment that included completion of a respiratory questionnaire and determination of DRS, skin-prick reactivity and exposure to tobacco smoke.

\section{Definitions}

PDA was defined as an affirmative response to the question "Does your child currently have asthma diagnosed by a doctor?" Parental asthma was defined as at least one parent ever with a history of PDA, as reported at enrolment. LRTI was defined as cough in the presence of upper respiratory tract infection. At all ages, atopy was defined as at least one positive skin test.

\section{Skin-prick testing}

At 1, 6 and 12 months of age, the skin-prick test [14] was used to determine skin reactivity to the following allergens: cows' milk, egg white, Dermatophagoides farinae, and Rye grass. At age 6 and 11 yrs, sensitivity to the following additional allergens was also assessed by the skin-prick test: D. pteronyssius, mixed grasses (combination No. 7), cat dander, dog dander, Aspergillus fumigatus, and Alterneria alternans. All allergens were supplied by Hollister-Stier, Elkhart, IN, USA. The positive control was histamine sulphate $\left(10 \mathrm{mg} \cdot \mathrm{mL}^{-1}\right)$ and the negative control was $0.9 \%$ saline. A positive skin test was defined as a weal $\geqslant 3 \mathrm{~mm}$ in its longest dimension.

\section{Childhood airway responsiveness}

At age 6 and 11 yrs, DRS was assessed using the rapid technique [15]. Briefly, increasing doses of inhaled histamine were administered from a hand-held dosimeter until either a $20 \%$ reduction in forced expiratory volume in one second (FEV1) occurred or the maximal cumulative dose was administered $(7.8 \mu \mathrm{mol})$. The DRS was calculated by dividing the percentage reduction in FEV1 by the cumulative dose of histamine administered [16]. In this population, DRS was negatively associated with forced mid-expiratory flow (FEF25-75); thus, reduced FEF25-75 was a potential confounder for increased AR, and FEF25-75 was considered in multiple regression analyses.

\section{Statistics}

Sex, parental asthma, atopy, LRTI in the first or second 6 months of life, and current smoking by any parent were considered dichotomous explanatory variables. The DRS was considered a continuous explanatory variable; the distribution of the DRS was skewed with a long right-hand tail and was $\log _{10}$ transformed prior to analysis (a constant of three was added to allow values of zero or less to be analysed).

Univariate analysis, by means of the Mann-Whitney U-test, was used to determine the relationship between the DRS at 6 or 11 yrs of age and each explanatory variable; significance was assumed at the $10 \%$ level. Using a forward step-wise approach, multivariate models were created to establish which explanatory variables identified in univariate analyses were acting independently of PDA at 6 or 11 yrs of age; all significant variables were considered, beginning with those of greatest influence. The outcome variable (relative increase in DRS) was computed by taking the antilogarithm of the estimate of difference in transformed DRS from simple linear regression or multiple linear regression models, to give the fold difference between levels of binary explanatory variables. Each variable that was significant in univariate, but not multivariate, analyses was added individually to the model that contained only significant variables in order for the effect of adjustment to be presented. Significance was assumed at the 5\% level in multivariate analysis.

\section{RESULTS \\ Subjects}

The original cohort numbered 253 individuals (142 (56\%) males). At age 1 month, atopic status was determined in 247 infants and, of these, two were atopic; at 6 and 12 months of age, the corresponding figures were 197 and 172. At age 6 yrs, 123 cohort members were assessed and, of these, atopy was determined in 112 (91\%) and DRS in 102 (83\%). At 11 yrs of age, 194 cohort members were assessed, and atopy was determined in $182(94 \%)$ and DRS in 176 (91\%). LRTI was reported by 41 out of $103(40 \%)$ infants during the first 6 months and 33 out of $86(38 \%)$ during the second 6 months of life. PDA was reported in 30 (24\%) children aged 6 yrs and 29 $(15 \%)$ aged 11 yrs. Figure 1 demonstrates the relationships between PDA, atopy and wheeze in the previous year for study subjects aged $6(n=113)$ and $11(n=183)$ yrs. Table 1 compares details of those individuals included in the analyses in this study with those in the whole cohort.

\section{Univariate analyses for dose-response slope at $\mathbf{6}$ yrs of age}

These data are summarised in table 2. At age 6 yrs, the DRS was positively associated with the following: at least one parent currently smoking (geometric mean $(95 \%$ confidence interval) 7.9 (4.4-13.2), $\mathrm{n}=42$, versus 4.1 (2.7-5.8), $\mathrm{n}=81$, for neither parent smoking; $\mathrm{p}=0.09)$; current atopy $(10.5$ (7.9-13.8), $\mathrm{n}=30$, versus 4.1 (2.8-5.7), $\mathrm{n}=63$, for nonatopic; $\mathrm{p}=0.007)$; and PDA (16.2 (7.3-32.7), $\mathrm{n}=22$, versus $3.6(2.6-4.6), \mathrm{n}=80$, for no PDA; $\mathrm{p}=0.004)$. The DRS at age 6 yrs was not associated with the other variables tested.
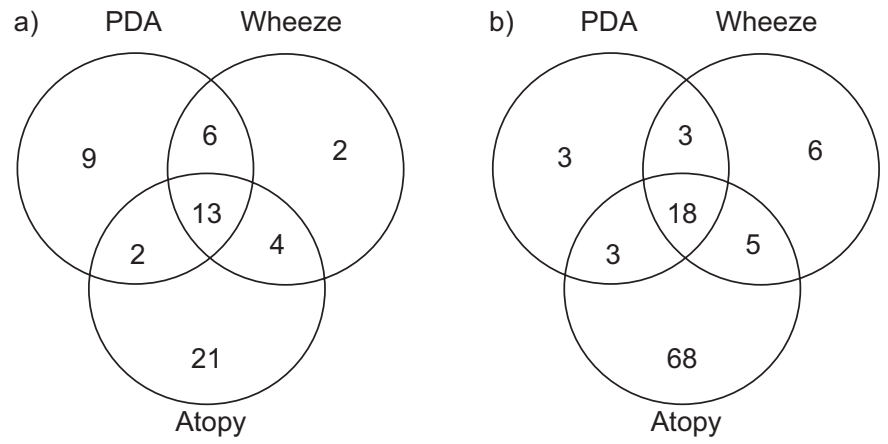

FIGURE 1. Venn diagrams demonstrating the relationship between atopy, wheeze in the past 12 months and physician-diagnosed asthma (PDA) for study subjects assessed at a) age 6 yrs (there were 56 with neither atopy, wheeze, nor PDA), and b) age 11 yrs (there were 77 with neither atopy, wheeze, nor PDA). The details of 10 individuals assessed at age 6 yrs, and 11 assessed at 11 yrs of age, were incomplete and could not be presented in this figure. 
TABLE 1 A comparison of the incidence of explanatory variables considered in this study between children where dose-response slope (DRS) was assessed at age 6 and 11 yrs with the whole cohort

\begin{tabular}{lccr} 
& DRS at age $\mathbf{6}$ yrs & DRS at age 11 yrs & Whole cohort \\
\hline Males & $53(55 / 102)$ & $58(102 / 176)$ & $56(142 / 253)$ \\
Atopy at $\mathbf{6}$ months & $8(7 / 86)$ & $12(18 / 151)$ & $11(21 / 197)$ \\
Atopy at $\mathbf{1 2}$ months & $4(3 / 81)$ & $7(10 / 136)$ & $8(13 / 172)$ \\
Parental asthma & $27(27 / 101)$ & $30(52 / 172)$ & $31(75 / 242)$ \\
LRTI in first $\mathbf{6}$ months & $38(21 / 56)$ & $39(31 / 79)$ & $40(41 / 103)$ \\
LRTI in second $\mathbf{6}$ months & $34(18 / 53)$ & $42(28 / 68)$ & $38(33 / 86)$ \\
Atopy at $\mathbf{6}$ yrs & $32(30 / 94)$ & $53(93 / 176)$ & $35(40 / 112)$ \\
Atopy at $\mathbf{1 1}$ yrs & & & $52(94 / 182)$ \\
PDA at $\mathbf{6}$ yrs & $21(22 / 102)$ & $15(27 / 176)$ & $33(40 / 123)$ \\
PDA at $\mathbf{1 1}$ yrs & & & $15(29 / 194)$ \\
\hline
\end{tabular}

Data are presented as \% (n/N). There were no differences between groups. LRTI: lower respiratory tract illness; PDA: physician-diagnosed asthma.

TABLE 2 Significance of potential factors associated with dose-response slope (DRS) at age 6 yrs

\begin{tabular}{lccc} 
Factor & Unadjusted relative increase in DRS & p-value & Adjusted relative increase in DRS \\
\hline Physician-diagnosed asthma & $1.59(1.32-1.93)$ & 0.004 & $1.31(1.06-1.62)$ \\
Current atopy & $1.31(1.08-1.59)$ & 0.007 & $1.30(1.08-1.57)$ \\
At least one parent currently smoking & $1.21(1.01-1.45)$ & 0.09 & $1.19(1.00-1.42)$ \\
Parental asthma & $1.13(0.93-1.38)$ & NS & 0.013 \\
Male sex & $1.08(0.90-1.28)$ & NS & 0.06 \\
Atopy at $\mathbf{1 2}$ months & $1.40(0.91-2.14)$ & NS & NS \\
LRTI before age $\mathbf{6}$ months & $1.02(0.83-1.25)$ & & \\
\hline
\end{tabular}

Data are presented as relative increase (95\% confidence interval). LRTI: lower respiratory tract illness; Ns: nonsignificant. The numbers of individuals in unadjusted analyses are presented in table 1. Data from 83 children were used in the multivariate analysis, where forced mid-expiratory flow was also considered $\left(r^{2}=0.34\right)$

\section{Multivariate analysis for dose-response slope at age 6 yrs}

At age $6 \mathrm{yrs}$, the DRS was positively and independently related to current atopy $(p=0.007)$, PDA $(p=0.013)$ and at least one parent currently smoking $(p=0.06$; table 2$)$. There was no interaction between the explanatory variables in this model.

\section{Univariate analyses for dose-response slope at age 11 yrs}

These data are summarised in table 3. At age $11 \mathrm{yrs}$, the DRS was positively associated with the following: parental asthma (geometric mean (95\% confidence interval) $3.3(2.3-4.4), \mathrm{n}=52$, versus $2.1(1.5-2.6), \mathrm{n}=120$, for those with no parental history of asthma; $\mathrm{p}=0.02)$; LRTI in the first 6 months of infancy (3.4 (2.3$5.8), \mathrm{n}=31$, versus $1.4(1.0-1.8), \mathrm{n}=48$, for those with no LRTI; $\mathrm{p}=0.002)$; atopy at 12 months of age $(7.4(2.1-23.5), \mathrm{n}=10$, versus 2.0 (1.6-2.4), $\mathrm{n}=126$, for nonatopic; $\mathrm{p}=0.07)$; current atopy (3.5 (2.5-4.5), $\mathrm{n}=93$, versus $1.4(1.1-1.6), \mathrm{n}=83$, for nonatopic; $\mathrm{p}<0.001)$; male sex $(2.6(2.0-3.2), \mathrm{n}=101$, versus 1.8 (1.4-2.3), $\mathrm{n}=74$, for females; $\mathrm{p}=0.039)$; and PDA (6.4 (3.1-11.0), $n=27$, versus $1.9(1.5-2.2), n=149$, for no PDA; $p=0.001)$. The DRS at 11 yrs of age was not associated with the other variables tested.

\section{Multivariate analysis dose-response slope at age 11 yrs}

At age $11 \mathrm{yrs}$, the DRS was independently and positively associated with PDA $(p=0.002)$, current atopy $(p=0.02)$ and
LRTI before 6 months of age $(p=0.018$; table 3; fig. 2). There was a significant interaction between atopy at 12 months and PDA at age 11 yrs $(\mathrm{p}=0.03)$; individuals with both atopy at age 12 months and PDA at age 11 yrs had greater DRS compared with other groups. There was no interaction between other explanatory variables in this model.

\section{DISCUSSION}

The current study was designed to test the hypothesis that there were factors other than asthma that were associated with DRS in children. The results were that atopy, tobacco-smoke exposure and early LRTI were associated with DRS, independent of asthma. In addition, there was evidence that, among children with asthma, the DRS was related to the early development of atopy. These findings, which have not been previously reported, could explain the inconsistent relationship between AR and asthma shown in other studies [1, 2].

The mechanism for increased AR is unclear, but appears to be complex, and may involve influences on both the airway epithelium and airway smooth muscle. Inflammatory cell infiltration of the airway epithelium, particularly with eosinophils, is thought to be important to the level of AR [17]. Several studies of adult populations have sought a relationship 
TABLE 3 Significance of potential factors associated with dose-response slope (DRS) at age $11 \mathrm{yrs}$

\begin{tabular}{|c|c|c|c|c|}
\hline Factor & Unadjusted relative increase in DRS & p-value & Adjusted relative increase in DRS & p-value \\
\hline Physician-diagnosed asthma & $1.24(1.13-1.36)$ & 0.001 & $1.31(1.15-1.49)$ & 0.002 \\
\hline $\begin{array}{l}\text { At least one parent currently } \\
\text { smoking }\end{array}$ & $0.96(0.89-1.32)$ & NS & & \\
\hline Parental asthma & $1.11(1.04-1.20)$ & 0.02 & $0.98(0.89-1.09)$ & 0.731 \\
\hline LRTI before 6 months & $1.21(1.09-1.34)$ & 0.002 & $1.14(1.04-1.24)$ & 0.018 \\
\hline
\end{tabular}

Data are presented as relative increase (95\% confidence interval). LRTI: lower respiratory tract illness; Ns: nonsignificant. The numbers of individuals in unadjusted analyses are presented in table 1 . Data from 79 children were used in the multivariate analysis, where forced mid-expiratory flow was also considered $\left(r^{2}=0.41\right)$. ${ }^{*}$ : atopy at 12 months was not significant when main effects were considered, but there was a significant positive interaction term between atopy at 12 months and physiciandiagnosed asthma $(p=0.031)$.

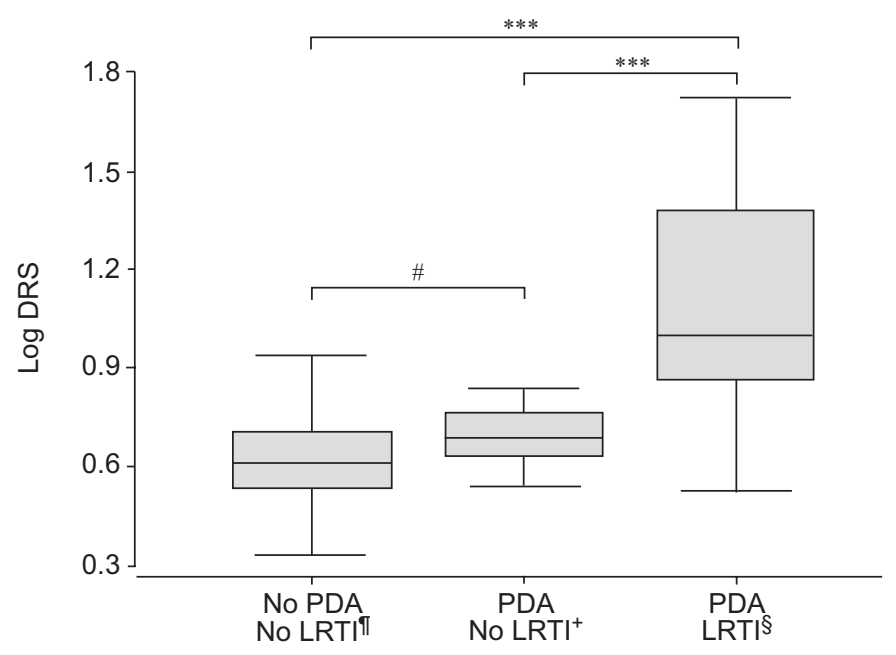

FIGURE 2. Box and whisker plot showing median and interquartile values for the dose-response slope (DRS) to inhaled histamine at age $11 \mathrm{yrs}$ for groups defined by the presence of lower respiratory tract illness (LRTI) before age 6 months and physician-diagnosed asthma (PDA) at age $11 \mathrm{yrs}$. Data are presented from the 79 children where early LRTI and PDA at age 11 yrs were determined; the influence of atopy was not considered here, but was considered in the analysis presented in table 3. Data from four individuals with LRTI before age 6 months and no PDA at age $11 \mathrm{yrs}$ are not shown, but were included in the analysis (values 0.69, 0.80, 0.87, and 0.91). ${ }^{* *}: p=0.001 ; *: p=0.08$ for comparisons using ANOVA with Bonferroni correction; ${ }^{\bullet}: \mathrm{n}=44 ;{ }^{+}: \mathrm{n}=24{ }^{\text {s. }} \mathrm{n}=7$.

between AR and inflammatory cell infiltrate in airway biopsy specimens with inconsistent findings [17]. The relationship between AR and airway biopsy material has not been studied in children; however, evidence from a small case series indicated that allergic airway inflammation was not necessarily present in asthmatic children with troublesome symptoms [18]. The importance of airway smooth muscle function to AR has been demonstrated in experiments where AR is greatly increased when deep inspirations are prevented during short periods of tidal breathing [19]. Although the current study was not able to determine mechanisms for $\mathrm{AR}$, the finding that the
DRS was related to factors other than atopy and asthma was consistent with the belief that AR was not solely determined by allergic mechanisms [17]

The current data suggested that the presence of atopy at 12 months of age was associated with a greater DRS among asthmatic children aged 11 yrs. VAN ASPEREN et al. [3] have previously concluded that atopic infants were likely to develop greater AR in childhood, but they could not relate early-onset atopy to asthma symptoms. Although increased AR in asthmatic children was often associated with atopy, not all atopic children had increased AR [4]. Thus, the age at onset of atopy rather than atopy per se may be important to the development of symptomatic increased AR. The number of individuals with atopy at age 12 months was relatively small, and the findings should be confirmed elsewhere.

Within the current longitudinal study, a positive relationship has been demonstrated between tobacco-smoke exposure and the DRS at age 6 but not $11 \mathrm{yrs}$, and this was consistent with another report [7]. Since the majority of children currently exposed to tobacco smoke were likely to have been similarly exposed in the past [20], the current authors were not able to determine whether prior exposure in infancy influenced the DRS at age 6 yrs. A transient association between tobaccosmoke exposure and AR in children could be attributable to a number of factors, including a reduction in passive exposure to parental tobacco smoke as older children have less close contact with their parents. Alternatively, later-onset atopy may mask the influence of earlier tobacco-smoke exposure. Although the effect of tobacco-smoke exposure on DRS might be transient, that on lung function persists [21].

LRTI in the first, but not second, 6 months of life influenced DRS almost 11 yrs later, independent of asthma. The clinical significance of increased DRS in the absence of asthma is not understood. Longitudinal studies have associated asymptomatic increased AR with reduced growth in FEV1 during late childhood [22] and accelerated decline in FEV1 during middle age [23]. Increased AR may, therefore, be associated with adverse respiratory outcome, even in the absence of asthma. 
Other studies have demonstrated an association between bronchiolitis in young infants admitted to hospital and increased AR in later childhood that was independent of atopy $[24,25]$. The current study adds to these previous studies $[24,25]$, since it demonstrated a positive influence on AR that was also independent of asthma, and this was in a cohort of individuals with relatively trivial respiratory illness that did not require hospital admission. The mere presence of a respiratory illness, rather than its severity, may have an important influence on AR in later life, although statistical associations, such as those reported in the current study, may not necessarily reflect causation [26]. Early LRTI was not associated with increased DRS at age 6 yrs, and it is believed that this apparently inconsistent finding was possibly a consequence of the smaller numbers studied and increased variability in measurements of DRS at age 6 yrs. It has been previously reported that bronchiolitis during the first 2 yrs of life was not associated with increased DRS in later childhood [27], and this is consistent with the current study where only respiratory illnesses during the first 6 months of life were considered. What remains to be determined is whether early LRTI is a cause of increased DRS in later childhood or, alternatively, whether lower respiratory tract symptoms and early-onset atopy are evidence of asthma and higher levels of DRS, which are only manifested later.

A major strength of this study was the longitudinal design, which, uniquely, has allowed consideration of factors influencing childhood AR that were present in infancy. Previous studies describing determinants of childhood AR either have not considered the influence of factors present in infancy [7, 11, 12], have relied upon retrospective reporting of events [8] or have considered only the influence of infantile atopy on childhood AR [3]. As in all longitudinal studies, not all individuals were assessed at every age, and this may have affected the outcomes. The current authors have demonstrated that those individuals included in the assessments in childhood were representative of the original cohort. Furthermore, the present data are consistent with many previous publications $[1,3,8,11,12,28]$, suggesting that incomplete follow-up has not significantly influenced the current findings, which are believed to substantially add to what is currently understood about AR and asthma in children.

The variation in DRS explained by the multiple linear regression models $\left(\mathrm{r}^{2}\right)$ was $<50 \%$, suggesting that other factors not assessed in this study may influence AR. Using the same methods as used the current study, PEAT et al. [16] reported that DRS to histamine may vary by $>20 \%$ when measurements are repeated $48 \mathrm{~h}$ apart. Measurements of AR appear to have a large inherent variability that is not explained by physiological factors, and methodological factors may be important.

In summary, this longitudinal study of a population not selected for asthma has demonstrated associations between the dose-response slope in children and factors other than asthma. Assessments of airway responsiveness have been advocated in the diagnosis of childhood asthma [29], but the data presented in the current study suggest that such assessments should be interpreted with caution, since factors other than asthma are influential.

\section{ACKNOWLEDGEMENTS}

The authors are grateful to their colleagues who have provided helpful assistance over the years of this cohort study. The authors are also very grateful for the ongoing cooperation of the families involved in the Osborne Park Family Asthma Study, Perth, Australia.

\section{REFERENCES}

1 Salome CM, Peat JK, Britton WJ, Woolcock AJ. Bronchial hyperresponsiveness in two populations of Australian schoolchildren. I. Relation to respiratory symptoms and diagnosed asthma. Clin Allergy 1987; 17: 271-281.

2 Sears MR, Burrows B, Herbison GP, Holdaway MD, Flannery EM. Atopy in childhood. II. Relationship to airway responsiveness, hay fever and asthma. Clin Exp Allergy 1993; 23: 949-956.

3 Van Asperen PP, Kemp AS, Mukhi A. Atopy in infancy predicts the severity of bronchial hyperresponsiveness in later childhood. J Allergy Clin Immunol 1990; 85: 790-795.

4 Sears MR, Burrows B, Flannery EM, Herbison GP, Hewitt CJ, Holdaway MD. Relation between airway responsiveness and serum $\mathrm{IgE}$ in children with asthma and in apparently normal children. New Engl J Med 1991; 325: 1067-1071.

5 Peat JK, Britton J, Salome C, Woolcock AJ. Bronchial hyperresponsiveness in two populations of Australian schoolchildren. II. Relative importance of associated factors. Clin Allergy 1987; 17: 283-290.

6 Stein RT, Holberg CJ, Morgan WJ, et al. Peak flow variability, methacholine responsiveness and atopy as markers for detecting different wheezing phenotypes in childhood. Thorax 1997; 52: 946-952.

7 Forastiere F, Corbo GM, Dell'Orco V, Pistelli R, Agabiti N, Kriebel D. A longitudinal evaluation of bronchial responsiveness to methacholine in children: role of baseline lung function, gender, and change in atopic status. Am J Respir Crit Care Med 1996; 153: 1098-1104.

8 Peat JK, Salome CM, Woolcock AJ. Factors associated with bronchial hyperresponsiveness in Australian adults and children. Eur Respir J 1992; 5: 921-929.

9 Laing IA, Goldblatt J, Eber E, et al. A polymorphism of the CC16 gene is associated with an increased risk of asthma. J Med Genet 1998; 35: 463-467.

10 Ramsay CE, Hayden CM, Tiller KJ, Burton PR, Goldblatt J, Le Souëf PN. Polymorphisms in the beta2-adrenoreceptor gene are associated with decreased airway responsiveness. Clin Exp Allergy 1999; 29: 1195-1203.

11 Forastiere F, Agabiti N, Corbo GM, et al. Passive smoking as a determinant of bronchial responsiveness in children. Am J Respir Crit Care Med 1994; 149: 365-370.

12 Martinez FD, Antognoni G, Macri F, et al. Parental smoking enhances bronchial responsiveness in nine-year-old children. Am Rev Respir Dis 1988; 138: 518-523.

13 Young S, Le Souëf PN, Geelhoed GC, Stick SM, Turner KJ, Landau LI. The influence of a family history of asthma and parental smoking on airway responsiveness in early infancy. New Engl J Med 1991; 324: 1168-1173.

14 Pepys J. Skin tests for immediate, type I, allergic reactions. Proc R Soc Med 1972; 65: 271-272. 
15 Yan K, Salome C, Woolcock AJ. Rapid method for measurement of bronchial responsiveness. Thorax 1983; 38: 760-765.

16 Peat JK, Salome CM, Bauman A, Toelle BG, Wachinger SL, Woolcock AJ. Repeatability of histamine bronchial challenge and comparability with methacholine bronchial challenge in a population of Australian schoolchildren. Am Rev Respir Dis 1991; 144: 338-343.

17 Brusasco V, Crimi E, Pellegrino R. Airway hyperresponsiveness in asthma: not just a matter of airway inflammation. Thorax 1998; 53: 992-998.

18 Jenkins HA, Cool C, Szefler SJ, et al. Histopathology of severe childhood asthma: a case series. Chest 2003; 124: 32-41.

19 Moore BJ, Verbergt LM, King GG, Pare PD. The effect of deep inspiration on methacholine dose-response curves in normal subjects. Am J Respir Crit Care Med 1997; 156: 1278-1281.

20 Le Souëf PN. Pediatric origins of adult lung diseases. 4. Tobacco related diseases begin in childhood. Thorax 2000; 55: 1063-1067.

21 Tager IB, Weiss ST, Munoz A, Rosner B, Speizer FE. Longitudinal study of the effects of maternal smoking on pulmonary function in children. New Engl J Med 1983; 309: 699-703.

22 Xuan W, Peat JK, Toelle BG, Marks GB, Berry G, Woolcock AJ. Lung function growth and its relation to airway hyperresponsiveness and recent wheeze. Results from a longitudinal population study. Am J Respir Crit Care Med 2000; 161: 1820-1824.

23 Rijcken B, Schouten JP, Xu X, Rosner B, Weiss ST. Airway hyperresponsiveness to histamine associated with accelerated decline in FEV1. Am J Respir Crit Care Med 1995; 151: 1377-1382.

24 Murray M, Webb MS, O'Callaghan C, Swarbrick AS, Milner AD. Respiratory status and allergy after bronchiolitis. Arch Dis Child 1992; 67: 482-487.

25 Pullan CR, Hey EN. Wheezing, asthma, and pulmonary dysfunction 10 years after infection with respiratory syncytial virus in infancy. BMJ (Clin Res Ed) 1982; 284: 1665-1669.

26 Clayton D, McKeigue PM. Epidemiological methods for studying genes and environmental factors in complex diseases. Lancet 2001; 358: 1356-1360.

27 Turner SW, Young S, Landau LI, Le Souëf PN. Reduced lung function both before bronchiolitis and at 11 years. Arch Dis Child 2002; 87: 417-420.

28 Sears MR, Burrows B, Herbison GP, Flannery EM, Holdaway MD. Atopy in childhood. III. Relationship with pulmonary function and airway responsiveness. Clin Exp Allergy 1993; 23: 957-963.

29 Taylor DR. Making the diagnosis of asthma. BMJ 1997; 315: $4-5$. 